\title{
Plasma Growth Hormone Responses to Growth Hormone-Releasing Factor in Normal Children and Children with Short Stature
}

\author{
Seizo SUWA, Noriyuki KATSUMATA, Hatae MAESAKA, \\ ATSUKo KUSAHANA AND YUMI YAMADA \\ Division of Endocrinology and Metabolism, Department of Pediatrics, \\ Kanagawa Children's Medical Center, Yokohama, Japan
}

\begin{abstract}
Plasma GH responses to GRF have been studied in 12 normal prepubertal children ( 6 boys and 6 girls) with normal height, 6 normal young adults and 90 patients with short stature due to various causes. Mean peak GH responses in normal boys and girls were $36 \pm 9 \mathrm{ng} / \mathrm{ml}(\mathrm{M} \pm \mathrm{SE})$ and $33 \pm 5 \mathrm{ng} / \mathrm{ml}$ respectively. Among 25 patients with idiopathic severe pituitary dwarfism, 16 cases showed peak GH to GRF less than $5 \mathrm{ng} / \mathrm{ml}, 3$ cases between 5 and $10 \mathrm{ng} / \mathrm{ml}$ and 6 more than $10 \mathrm{ng} / \mathrm{ml}$. There was a negative correlation between chronological age and peak GH responses to GRF in these 25 pituitary dwarfism. However, no correlation was observed in patients with partial idiopathic dwarfism (6 cases), normal short children (31 cases) and normal children. GH responses to GRF were blunted in organic pituitary dwarfism and primary hypothyroidism, but normal in deprivation dwarfism and Turner's syndrome. The responses in normal short children were variable, some children showed blunted but some normal. Acute exogenous GH administration suppressed the responsiveness of somatotrophs to GRF, but this was easily reversible even after chronic administration of $\mathrm{GH}$ for one year in normal short children who showed increased growth rate during the GH treatment.
\end{abstract}

Since growth hormone-releasing factor (GRF) was isolated and characterized (Guillemin et al., 1982; Rivier et al., 1982), many clinical and basical reports on GRF have been published (Frohman and Jansson, 1986). Synthetic GRF is now available for clinical testing as a method of assessing GH secretion in physiological and pathological conditions, and it is thought that direct stimulating effect of GRF on somatotrophs is faster and greater than other secretogogues (Laron and Bauman, 1986). However,

* This study was presented at the International Symposium on GRF, GH and Somatomedin (Tokyo) 1986. much still remains to be clarified with respect to the clinical usefulness of GRF as diagnostic agent.

We will present some results of our clinical experiences on GRF test in normal children with growth retardation.

\section{Subjects and Methods}

Subjects examined in our study are illustrated in Tab. 1. Twelve normal children with normal height consisted of 6 prepubertal boys (5-11 years) and 6 prepubertal girls (4-9 years). Thirty-one short children with normal GH secretion to secretogogues other than GRF were 
Table 1. List of subjects examined.

\begin{tabular}{lc}
\hline \hline \multicolumn{1}{c}{ Diagnosis } & $\begin{array}{c}\text { No. of } \\
\text { Cases }\end{array}$ \\
\hline Normal Children (Normal Height) & 12 \\
Normal Adult & 6 \\
Idiopathic Pituitary Dwarfism & \\
$\quad$ severe* & 25 \\
$\quad$ partial** & 6 \\
Organic Pituitary Dwarfism & \\
$\quad$ severe* & 9 \\
$\quad$ partial** & 2 \\
Primary Hypothyroidism & 4 \\
Deprivation Dwarfism & 5 \\
Turner's Syndrome & 6 \\
Delayed Adolescence with Short Stature & 2 \\
Normal Short Children & 31 \\
\hline
\end{tabular}

* Severe : Peak GH Responses to Provocative Tests Other Than GRF $\leqq 5$ $\mathrm{ng} / \mathrm{ml}$ (RIA)

** Partial : $5 \mathrm{ng} / \mathrm{ml}<$ Peak $\mathrm{GH} \leqq 7 \mathrm{ng} / \mathrm{ml}$

named as normal short children. Severe GH deficiency was defined as peak GH responses to provocative tests other than GRF was less than $5 \mathrm{ng} / \mathrm{ml}$ and partial $\mathrm{GH}$ deficiency as between 5 and $7 \mathrm{ng} / \mathrm{ml}$.

A single bolus of $1 \mu \mathrm{g} / \mathrm{kg}$ of synthetic human
GRF-44 was administered iv, and plasma GH was measured by radioimmunoassay (RIA) during a 2 hours sampling period. Plasma GH was also determined by high sensitive immunoradiometric assay (IRMA : Sucrosep hGH from BootsCelltech Diagnostics Lt.) in several patients with severe GH deficiency. Synthetic GRF-44 which we used was kindly supplied mainly by Sumitomo Pharmaceutical Company (Osaka, Japan). Statistical analysis was conducted by Student's $t$-test.

\section{Results}

\section{Normal children}

The Fig. 1 shows GH responses to GRF in the normal prepubertal boys and girls. Mean peak GH levels were $36 \pm 9 \mathrm{ng} / \mathrm{ml}$ $(\mathrm{M} \pm \mathrm{SE})$ and $33 \pm 5 \mathrm{ng} / \mathrm{ml}$ respectively. Time of peak GH in boys was between 10 and 20 minutes after GRF injection, and between 10 and 45 minutes in girls.

There is no significant difference between these two normal groups $(p<0.05)$. And these values were similar to those of 6 normal young adults examined, who showed

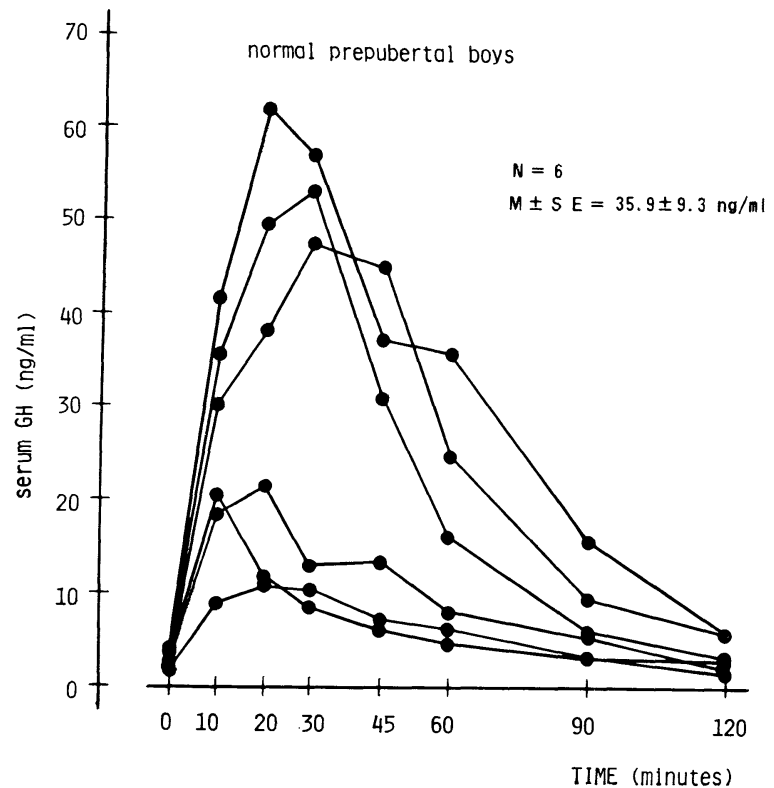

normal prepubertal girls

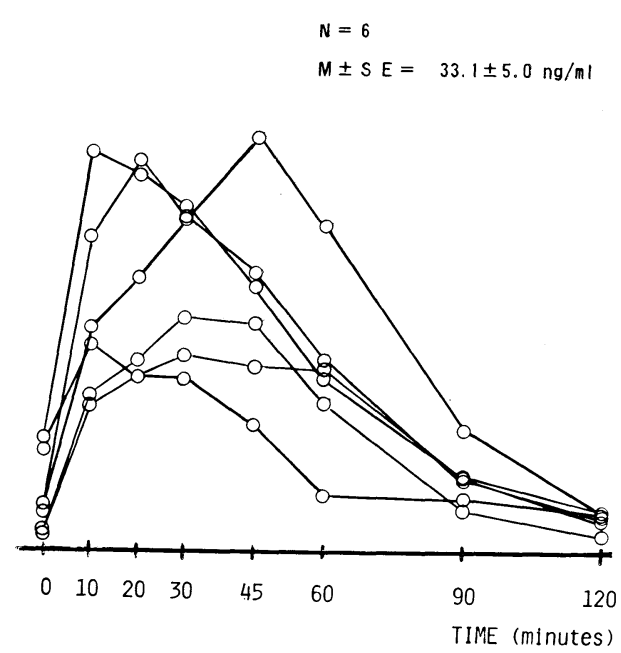

Fig. 1. Plasma GH responses to synthetic human GRF-44 $(1 \mu \mathrm{g} / \mathrm{kg}$, iv) in normal prepubertal boys (left) and girls (right). 


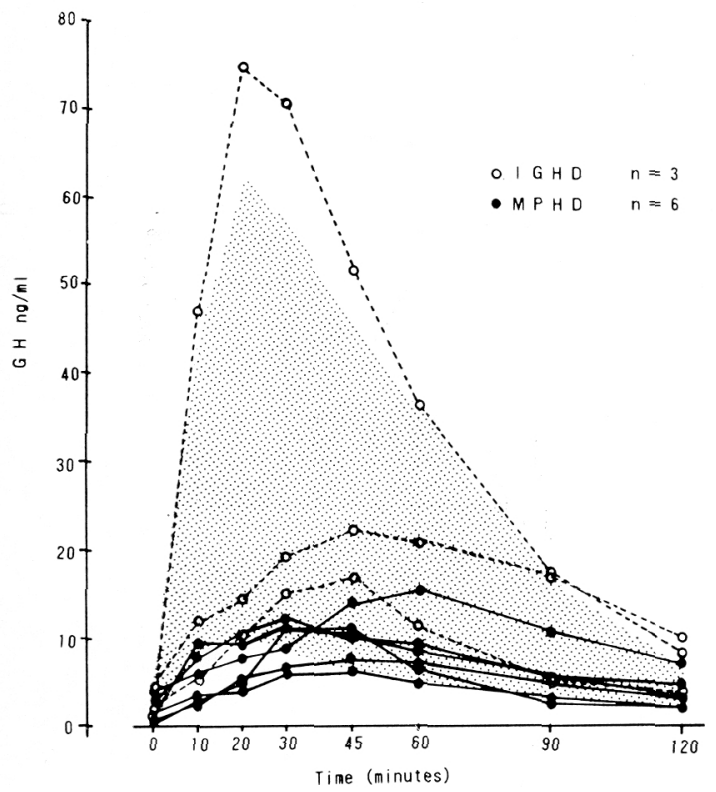

Fig. 2. Plasma GH responses to GRF in idiopathic severe pituitary dwarfism. 16 cases with peak $\mathrm{GH} \leqq 5 \mathrm{ng} / \mathrm{ml}$ were precluded in the figure. IGHD: isolated $\mathrm{GH}$ deficiency; MPHD: multiple pituitary hormones deficiency.

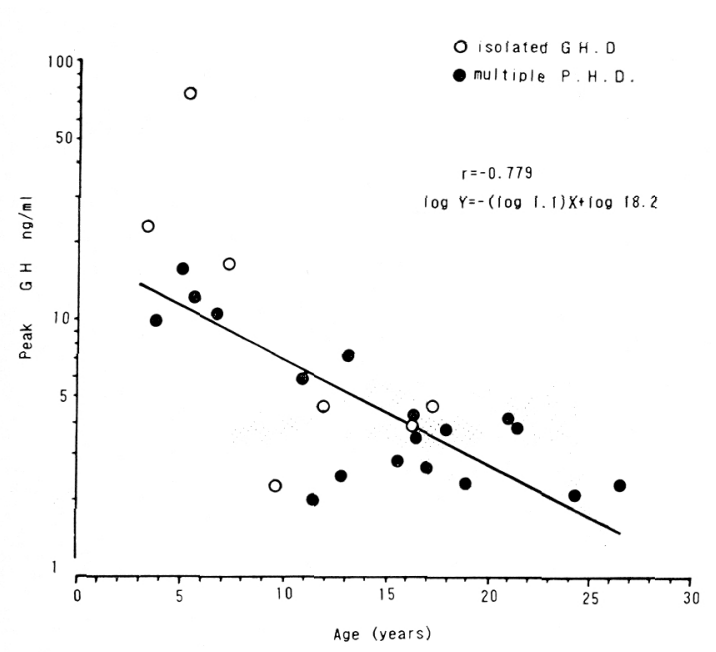

Fig. 3. Correlation between chronological age and peak GH responses to GRF in idiopathic severe pituitary dwarfism. the mean peak $\mathrm{GH}$ of $48 \pm 18 \mathrm{ng} / \mathrm{ml}$.

\section{Pituitary dwarfism}

Among 25 cases with idiopathic severe pituitary dwarfism, 16 cases showed peak $\mathrm{GH}$ to GRF less than $5 \mathrm{ng} / \mathrm{ml}$, and the pattern of $\mathrm{GH}$ responses to GRF in the rest 9 cases are shown in Fig. 2. Of these 9 cases, 6 had the peak GH more than 10 $\mathrm{ng} / \mathrm{ml}$. Except one case, plasma GH rose slower and the time of peak $\mathrm{GH}$ was later than normal.

Fig. 3 demonstrates the correlation
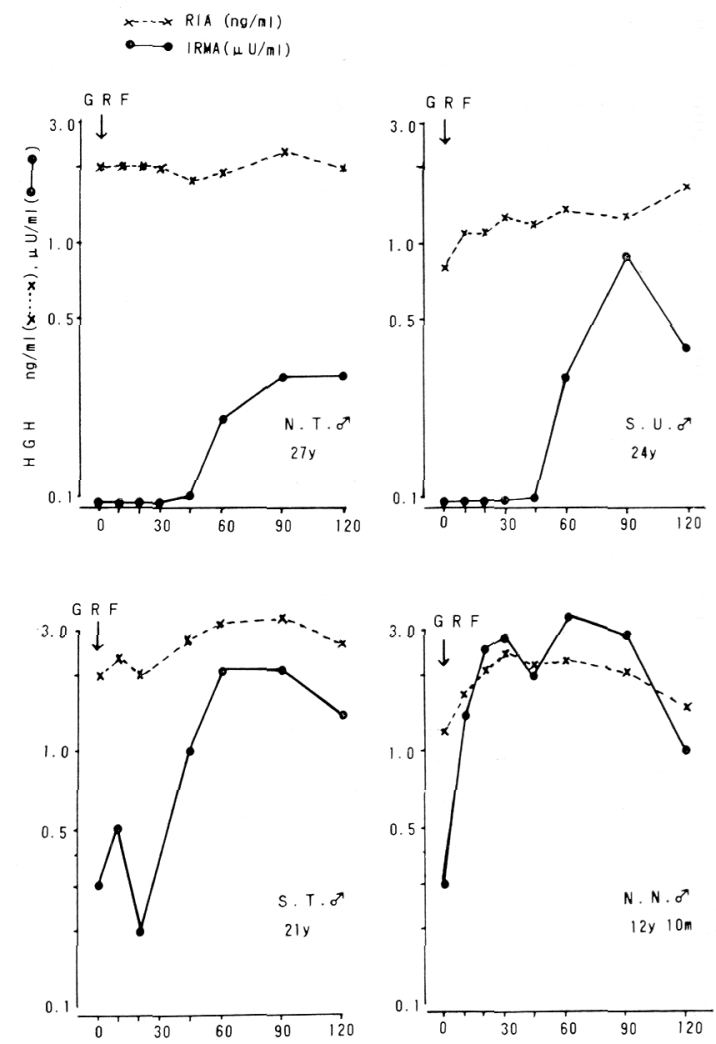

Fig. 4. Plasma $\mathrm{GH}$ profiles in 4 cases with idiopathic severe pituitary dwarfism. $\mathrm{GH}$ measured by RIA kit showed blunted responses to GRF, but GH measured by high sensitive immunoradiometric assay showed definite rise after GRF injection. The higher the age of the patients, the less peak $\mathrm{GH}$ levels were observed. 
between chronological age and peak GH responses to GRF in severe idiopathic pituitary dwarfism. The vertical axis of the Fig. 3 is indicated as log. scale. The correlation coefficience is -0.8 . The correlation is higher in the cases before 15 years old, and lower after that.

Plasma $\mathrm{GH}$ was determined by high sensitive immunoradiometric assay (IRMA) in 4 cases with low-responder to GRF. The results are shown in Fig. 4. Plasma GH levels measured by routine RIA kit showed minimal rise in response to GRF, but $\mathrm{GH}$ measured by IRMA showed clear rise in response to GRF. The decreasing tendency of peak GH with chronological age was observed.

Fig. 5 shows also the correlation between peak GH responses to GRF and chronological age in normal children, normal short children and idiopathic partial GH deficiency. There was completely no correlation in each group at all.

Idiopathic partial GH deficiency, aged 6 to 14 years, showed normal response to GRF in terms of peak GH levels and the time of peak GH (Fig. 6).

The responses to GRF in organic pituitary dwarfism are shown in Fig. 7. The

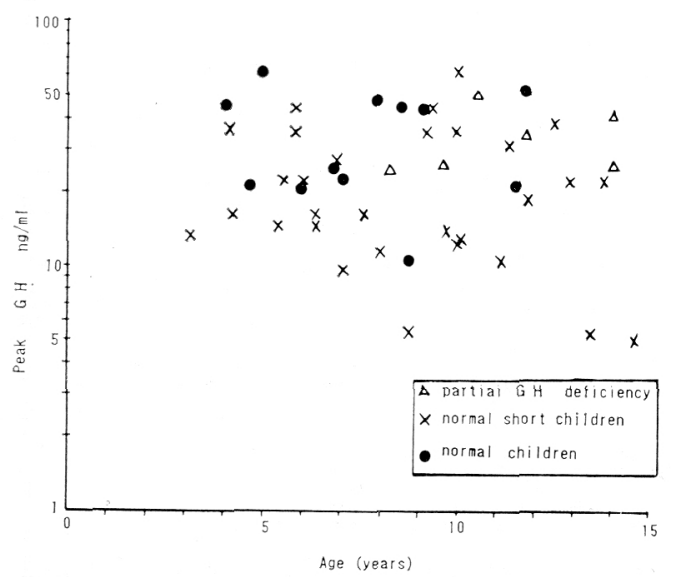

Fig. 5. No correlation between age and peak GH responses to GRF was observed in normal children, normal short children and patients with partial GH deficiency.

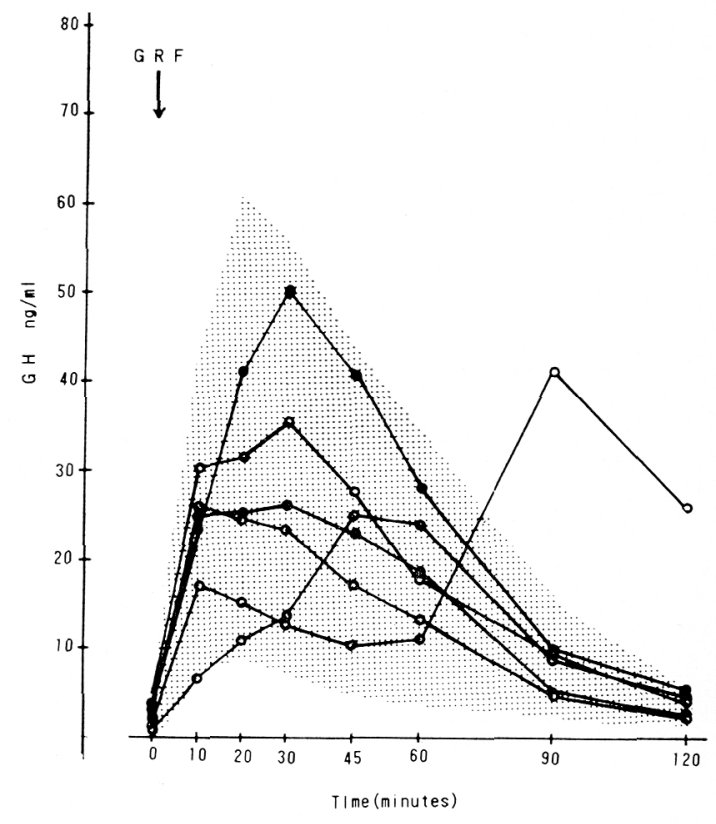

Fig. 6. GRF tests in idiopathic partial GH deficiency showing almost normal responses.
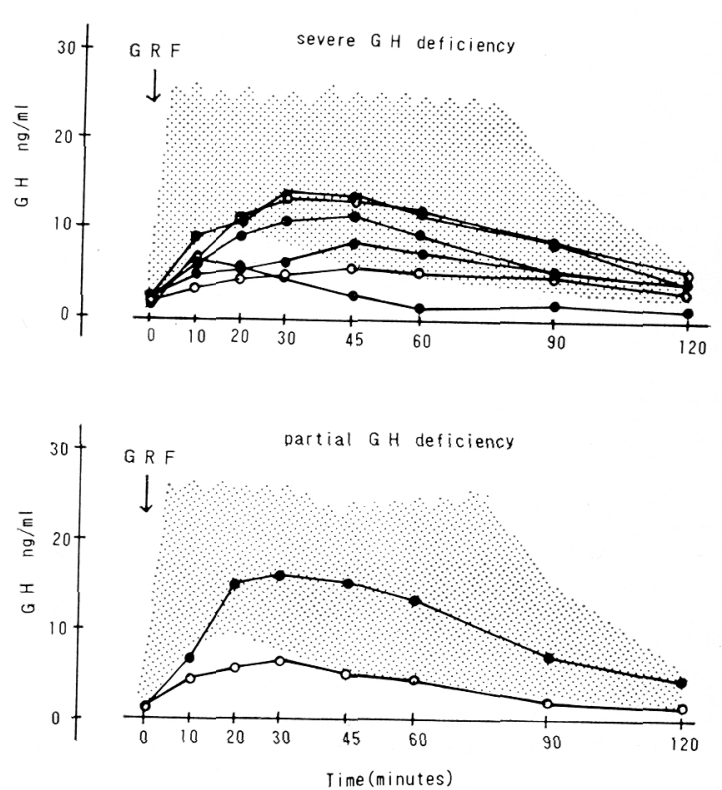

Fig. 7. GRF tests in organic pituitary dwarfism. Both of the patients with severe and partial GH deficiency showed blunted, but over $5 \mathrm{ng} /$ $\mathrm{ml}$ responses. 
Table 2. List of primary hypothyroidism.

\begin{tabular}{|c|c|c|c|c|c|c|c|}
\hline Name & Sex & $\begin{array}{l}\text { Age } \\
\text { (yr) }\end{array}$ & $\begin{array}{c}\text { TSH } \\
(\mu \mathrm{U} / \mathrm{ml})\end{array}$ & $\begin{array}{c}\mathrm{T}_{4} \\
(\mu \mathrm{g} / \mathrm{ml})\end{array}$ & $\begin{array}{c}\mathrm{FT}_{4} \\
(\mathrm{ng} / \mathrm{dl})\end{array}$ & $\begin{array}{c}\mathrm{T}_{3} \\
\text { (ng/dl) }\end{array}$ & $\begin{array}{l}\text { Peak GH } \\
\text { to ITT } \\
\text { (ng/ml) }\end{array}$ \\
\hline H. M. & $\mathrm{F}$ & $\begin{array}{ll}7 & 1 / 12\end{array}$ & 1,023 & $<1.0$ & $<0.2$ & 20 & 8.7 \\
\hline K. K. & M & $107 / 12$ & 240 & 3.5 & 0.3 & 80 & 4.2 \\
\hline F. A. & $\mathrm{F}$ & $121 / 12$ & 404 & $<1.0$ & $<0.2$ & 20 & 3.1 \\
\hline F. F. & M & $147 / 12$ & 16 & 6.8 & 1.0 & 110 & 15.9 \\
\hline
\end{tabular}

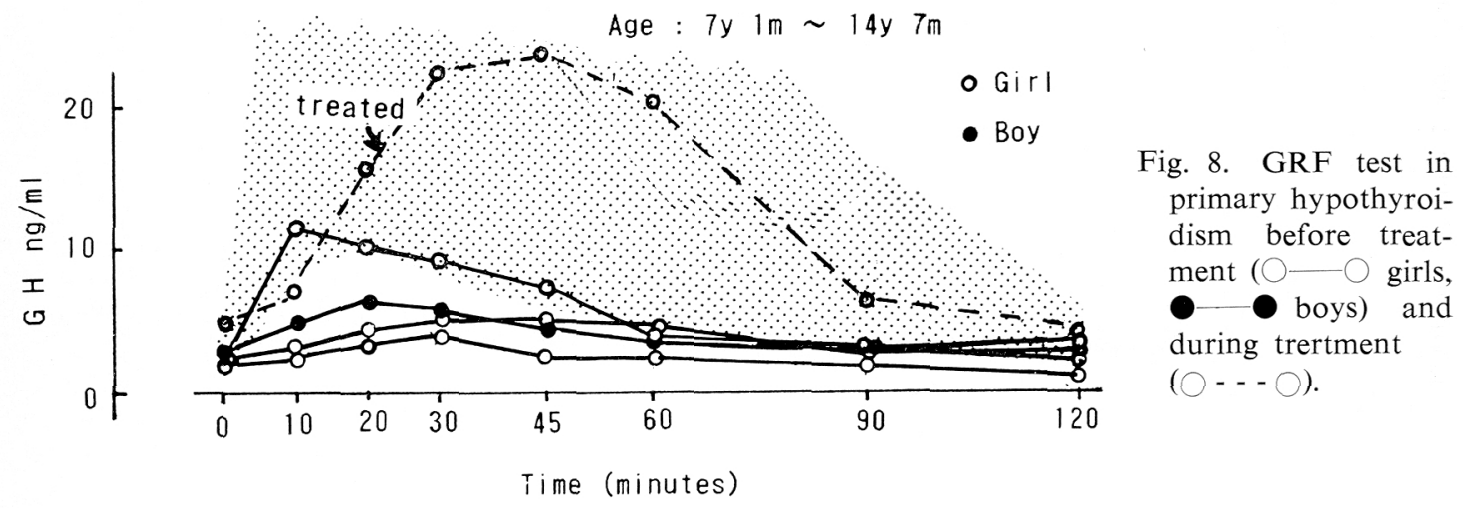

results of 6 cases with severe $\mathrm{GH}$ deficiency are shown on the upper panel, and 2 with partial ones on the lower panel. All of these 8 cases exhibited peak $\mathrm{GH}$ higher than $5 \mathrm{ng} / \mathrm{ml}$. But the pattern of the curves were low and blunted.

\section{Primary hypothyroidism}

The GH responses to GRF in 4 cases with juvenile onset primary hypothyroidism were examined. Peak GH responses to insulin induced hypoglycemia (ITT) were severely suppressed in 2 cases, mild in one and normal in one (Tab. 2). GH responses to GRF in these patients are shown in Fig. 8. Minimal GH rises were observed in 3 cases who showed low GH response to ITT. However one case who responded normally to ITT showed normal GH response to GRF, and one non-responder before treatment showed normal after thyroxine treatment.

\section{Turner's syndrome}

Fig. 9 shows the pattern of $\mathrm{GH}$ responses to GRF in 6 cases with Turner's syndrome aged between 5 and 13 years.

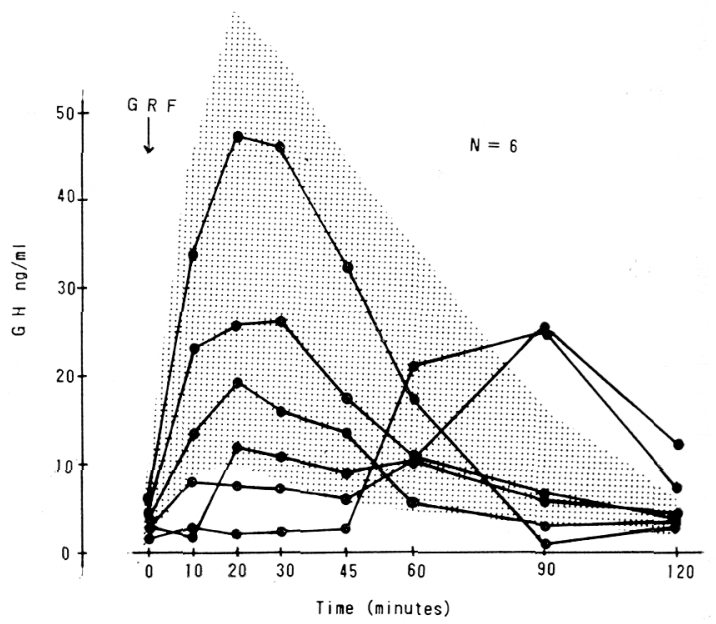

Fig. 9. GRF tests in Turner's syndrome. 
Four of them showed normal but 2 showed delayed responses.

\section{Deprivation dwarfism}

We examined $\mathrm{GH}$ secretion in 5 cases with deprivation dwarfism. Fig. 10 shows GH secretion in ITT (on the left), and during sleep (on the right). Four of them showed subnormal GH secretion. GRF test in these 5 cases showed almost normal GH responses (Fig. 11).

\section{Normal short children}

The results of GRF test in 31 cases with normal short children are illustrated in Fig. 12. Some of them showed normal, some blunted or delayed and others very low responses. Peak GH responses to GRF $(22.3 \pm 2.5 \mathrm{ng} / \mathrm{ml})$ were compared with maximum peak $\mathrm{GH}$ responses to several secretogogues other than GRF $(22.4 \pm 2.8 \mathrm{ng} / \mathrm{ml})$. The mean peak GH levels of each responses did not differ significantly, but there was no correlation between the two. We could
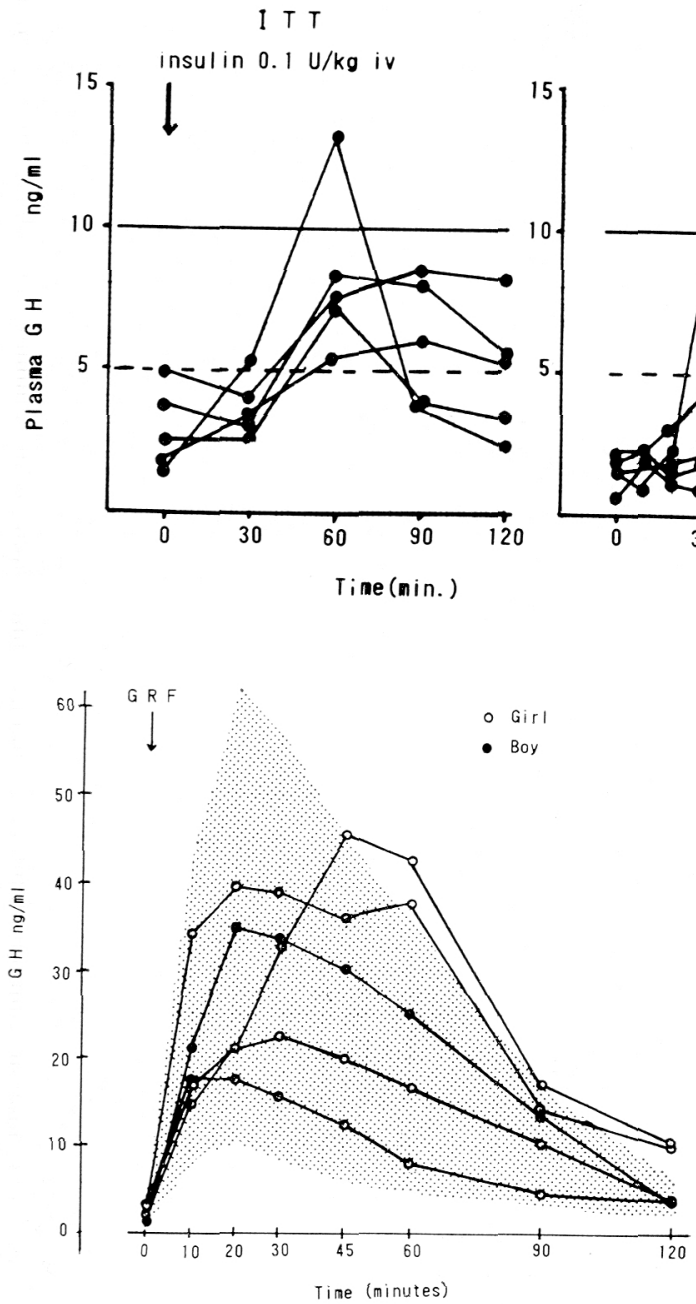

Fig. 11. GRF tests in 5 patients with deprivation dwarfism.

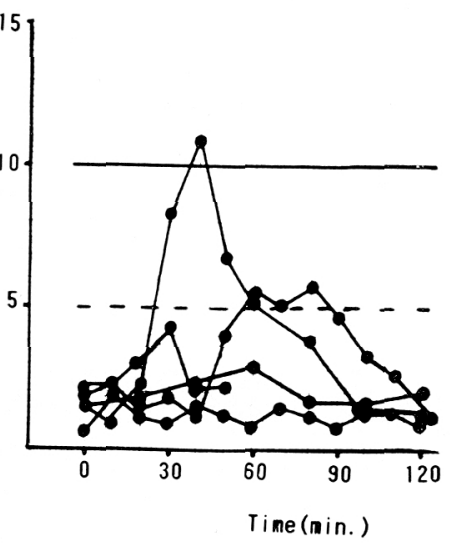

Fig. 10. Plasma GH responses to insulin induced hypoglycemia and during sleep in 5 patents with deprivation dwarfism.

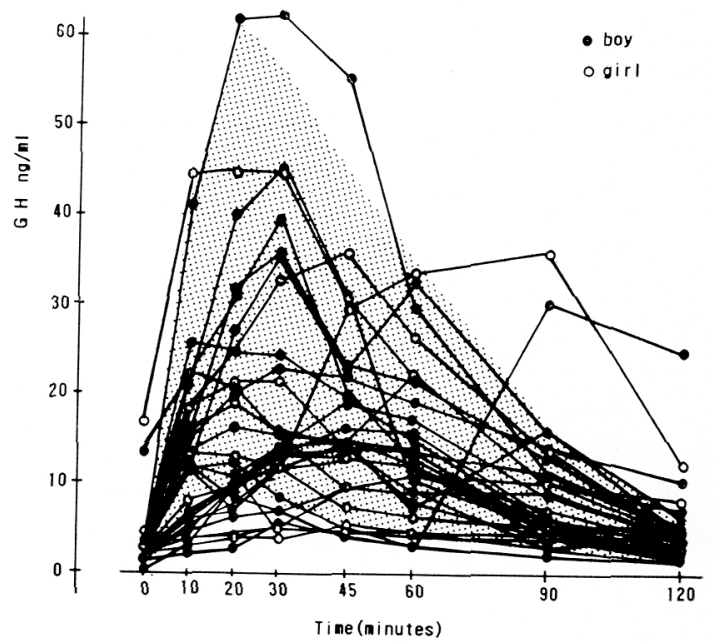

Fig. 12. GRF tests in normal short children. 


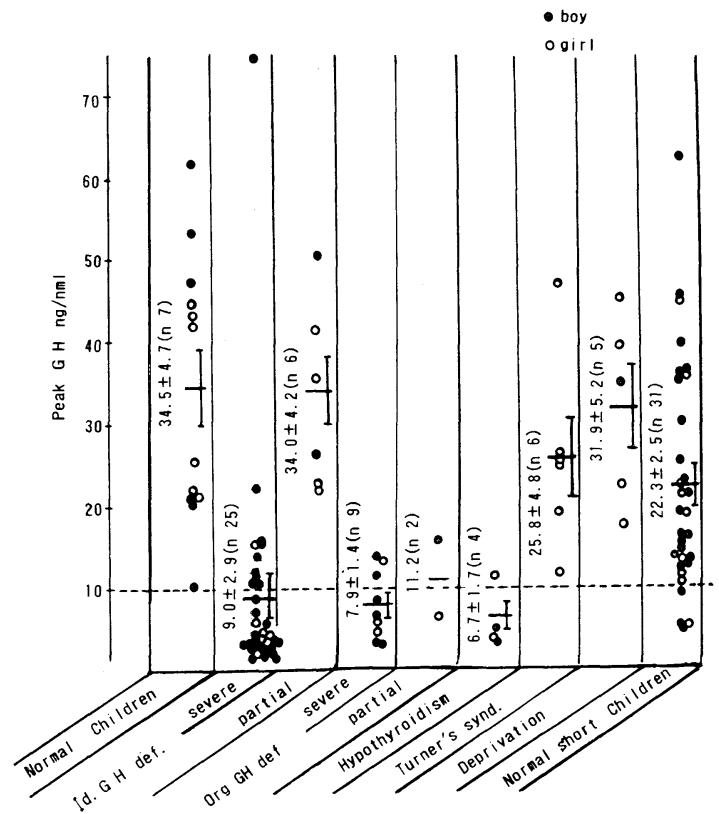

Fig. 13. Peak GH responses to GRF in normal children and short children due to various causes.

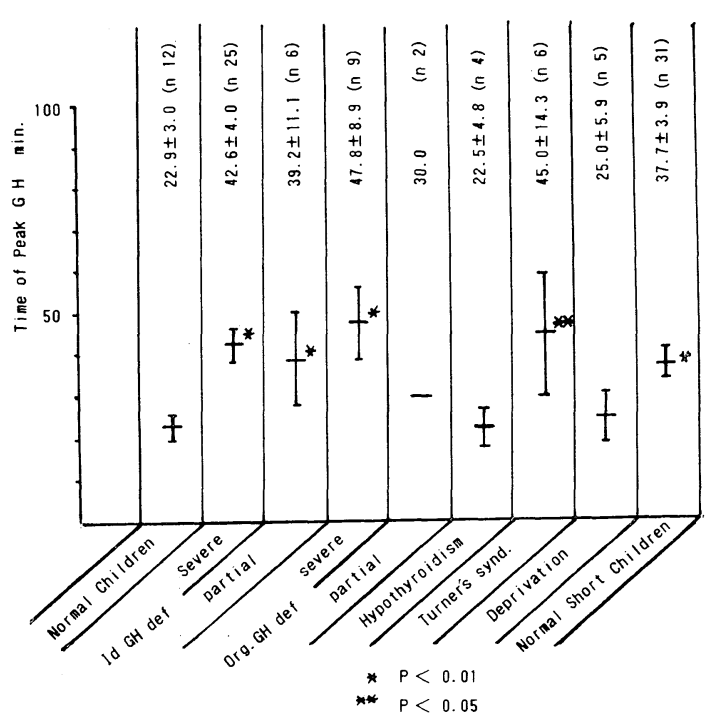

Fig. 14. Time of peak GH responses to GRF in normal children and short children due to various cases.

Table 3. Normal short children and patients with constitutional delayed adolescence with slow growth treated hGH for 1 year. 2 cases with delayed adolescence showed blunted $\mathrm{GH}$ responses to provocative tests, but normal after testosterone priming.

(1) Normal Short Children

\begin{tabular}{|c|c|c|c|c|c|c|c|c|}
\hline \multirow{2}{*}{ Name } & \multirow{2}{*}{ Age (Yr) } & \multirow{2}{*}{ Sex } & \multirow{2}{*}{$\mathrm{Ht}(\mathrm{cm})$} & \multirow{2}{*}{$\mathrm{SD}$} & \multirow{2}{*}{ BA } & \multicolumn{3}{|c|}{ Peak GH (ng/ml) } \\
\hline & & & & & & ITT & Arg & Sleep \\
\hline M. H. & $4-6$ & M & 94.9 & -2.2 & $2-8$ & 10.6 & 9.2 & 3.5 \\
\hline O. T. & $6-5$ & M & 98.5 & -3.7 & $3-2$ & 26.9 & 12.9 & 8.0 \\
\hline H. K. & $7-1$ & M & 100.8 & -3.8 & $4-11$ & 22.9 & 6.4 & - \\
\hline W. S. & $9-4$ & M & 114.6 & -3.1 & $6-0$ & 14.4 & 12.6 & 18.5 \\
\hline O. K. & $10-0$ & M & 100.8 & -5.7 & $7-0$ & 11.8 & 4.8 & 16.8 \\
\hline I. M. & $11-9$ & M & 130.4 & -2.2 & $12-9$ & 23.0 & 20.8 & 16.4 \\
\hline M. I. & 4-9 & $\mathrm{F}$ & 89.5 & -3.7 & $2-6$ & 19.6 & 30.1 & 8.8 \\
\hline O. R. & $9-3$ & $\mathrm{~F}$ & 115.9 & -2.6 & $6-6$ & 35.8 & 12.9 & 14.6 \\
\hline \multicolumn{9}{|c|}{ (2) Delayed Adolescence } \\
\hline I. $\mathrm{H}$. & $8-4$ & $\mathbf{M}$ & 112.2 & -2.6 & $5-11$ & $\begin{array}{c}4.6 \\
(22.7)^{*}\end{array}$ & 5.4 & 3.5 \\
\hline A. D. & $12-4$ & M & 127.2 & -2.8 & $8-8$ & $\begin{array}{c}3.9 \\
(30.0)^{*}\end{array}$ & 5.8 & 4.2 \\
\hline
\end{tabular}

\footnotetext{
* Testosterone Priming
} 
not find any correlation between peak GH responses to GRF and plasma $\mathrm{Sm}-\mathrm{C}$ in these normal short children. Two cases showed high Sm-C levels with low GH response to GRF, a few cases showed low $\mathrm{Sm}-\mathrm{C}$ but normal $\mathrm{GH}$ responses.

Levels and times of peak $G H$ responses to GRF

The results of $\mathrm{GH}$ responses to GRF in normal and growth retarded children which we examined are summerized in Fig. 13. Fig. 14 shows the time of peak GH levels in GRF test. When compared with normal children, not only GH deficiency, but also Turner's syndrome and normal short children showed significantly delayed peak time.

Effects of exogenous $h G H$ on GRF test

We examined GRF test before and after 1 year treatment with pituitary derived $\mathrm{GH}$ in 8 cases with normal short children and 2 cases with constitutional delayed adolescence with slow growth. Age, sex, height, bone age and results of $\mathrm{GH}$ secretion tests other than GRF test are shown in Tab. 3.

Growth rate before and during $\mathrm{GH}$
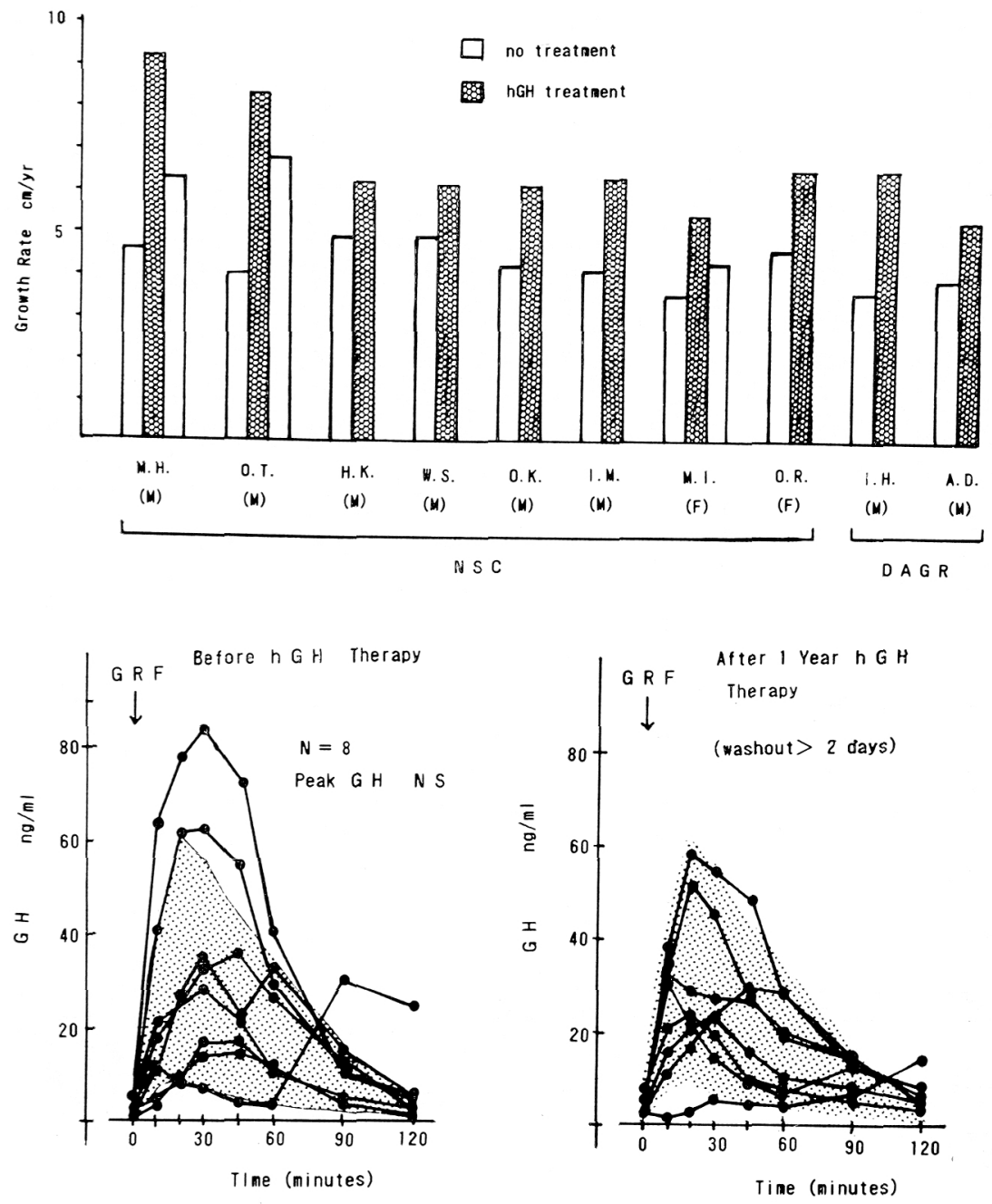

Fig. 15. Growth rate before and during hGH therapy $(0.5$ $\mathrm{U} / \mathrm{kg} / \mathrm{w}$ ) in normal short children (NSC) and constitutional delayed adolescence with growth retardation (DAGR).

Fig. 16. GRF tests before and after one year treatment with hGH in normal short children. GRF tests were done after more than 2 days washout period. 

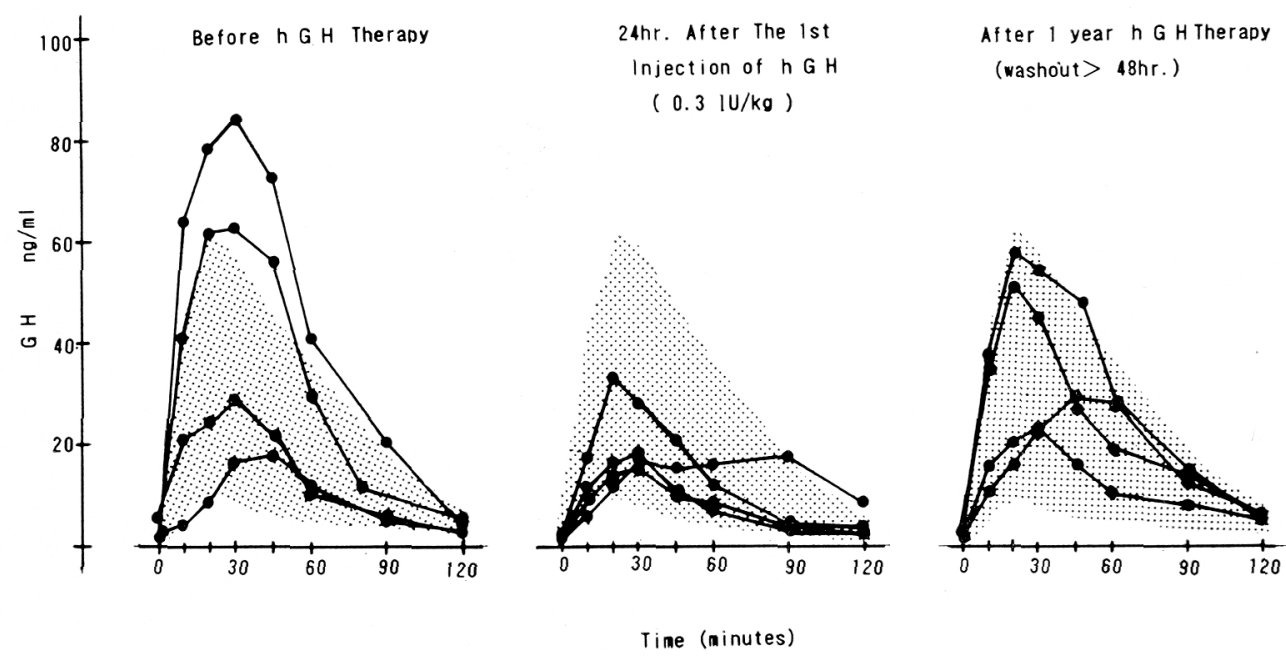

Fig. 17. GRF tests in normal short children. Acute $\mathrm{GH}$ administration diminished the $\mathrm{GH}$ response to GRF.

But the GH response to GRF after more than 2 days washout period, showed normal ever after chronic $\mathrm{GH}$ administration for one year.

treatment for 1 year are illustrated in Fig. 15. All of the cases showed increased growth rate during $\mathrm{GH}$ treatment. No antibody to $\mathrm{GH}$ was found during $\mathrm{GH}$ treatment.

No statistical difference $(\mathrm{p}<0.05)$ in the $\mathrm{GH}$ responses to GRF between before and after the GH treatment was found (Fig. 16). The GRF tests after GH treatment were done after more than 2-days washout period. However, the GH responses to GRF which was done $24 \mathrm{hrs}$ after the 1st GH in jection, showed diminished pattern in 4 cases (Fig. 17). But after 1-year GH therapy $(0.5 \mathrm{U} / \mathrm{kg} / \mathrm{w})$, the results of GRF test which was proceeded after more than 2 days washout interval showed similar pattern to that before the therapy.

\section{Discussion}

It has been already published that peak GH responses to GRF tended to decline with age and most of the normal subjects over 40 years showed low or minimal re- sponses to GRF (Shibasaki et al., 1984; Pavlov et al., 1986). However, only a few paper regarding responsiveness to GRF in normal children have been published. Our data on the GH responses to GRF in prepubertal children are consistent with other reports published on prepubertal children (Chihara et al., 1985 ; Pintor et al., 1986), pubertal subjects (Gelato et al., 1986), young adults (Shibasaki 1984; Gelato 1984) and infants (Shimano 1985). Gelata et al., published GH responses to GRF in 90 children of different pubertal stages (Gelato 1986). Only the responses in boys at midpuberty were somewhat lower, however they discussed that the chronic changes occuring in normal development are quite different from the acute experimental effects, and not all of their observations points towards such a linkage. Therefore, it seems likely that the magnitude of GH response to GRF are quite similar in normal subjects from infant through young adult age. Inspite of the GH responsiveness to GRF in puberty being similar to that in prepuberty, plasma immunoreactive GRF concentrations were 
reported to be higher in puberty than before it (Argente 1986). On the other hand, plasma $\mathrm{Sm}-\mathrm{C}$ levels has been reported to be higher in the pubertal subjects. Much studies are necessary to elucidate the relationships between the higher Sm-C levels, the higher GRF levels and the similar responsiveness of $\mathrm{GH}$ to exogenous GRF in puberty.

Controversy exists concerning the responsiveness of GH to GRF in patients with pituitary dwarfism. It has been reported that there was a negative lineal correlation between chronological age and peak GH responses to GRF in pituitary dwarfism (Schriock 1984). However, our data suggest that the relationship between peak GH responses to GRF and age is not simple lineal correlation, but seems to be exponential-like one. And even in the lowresponders (peak $\mathrm{GH}$ responses to $\mathrm{GRF} \leqq$ $5 \mathrm{ng} / \mathrm{ml}$ ), the similar decreasing tendency of peak GH to GRF with age was observed, when plasma $\mathrm{GH}$ was measured by high sensitive method. This negative correlation did not exist in normal children, patients with partial GH deficiency who showed normal GH responses to GRF, and normal short children. These results implies the longer the duration of endogenous GRF deficiency, the less the responsiveness of somatotrophs to acute exogenous GRF challenge, in other words, GRF deficiency gradually makes somatotrophs atrophy with time. Therefore, a single bolus iv injection of GRF is not necessarily useful tool to differentiate the disturbance of $\mathrm{GH}$ secretion in pituitary gland from that in hypothalamus in the patients with idiopathic pituitary dwarfism. The causes and duration of the organic brain lesions in organic pituitary dwarfism were variable, so we could not determine by GRF test if the lesion situated in hypothalamus or pituitary or both. It has been published that multiple-pulse GRF administrations change the magnitude of GH response (Schriock 1986), suggesting that diminished capacity of somatotrophs to secrete $\mathrm{GH}$ is reversible by long-term pulsatile GRF administrations in the patients with hypothalamic GRF deficiency.

It has been published that patients with primary hypothyroidism show low GH responses to GRF which are resolved in euthyroid state (Frohman, 1986; Williams 1985). We also demonstrated the similar results in children. These results indicates that thyroid hormone deficiency suppress GH production in somatotrophs primarily, which is reversible with thyroxine treatment.

$\mathrm{GH}$ secretion in deprivation dwarfism is variable and complicated. Some severe cases show blunted GH secretion to secretogogues and in physiological states. GRF test in deprivation dwarfism has not been published. Our data on GRF test in this syndrome implied that functional abnormality of GH secretion in deprivation dwarfism existed not in the pituitary itself, but in the hypothalamic level.

The GH responses to GRF in normal short children were variable and most complicated, but the mean peak GH levels was significantly lower than normal children, implying that many cases of normal short children may have any abnormal GH regulating mechanism. It is possible that causes of normal short children are heterogeneous ones, therefore the results of $\mathrm{GH}$ responses to secretogogues including GRF are variable. In further investigation, we should divide these short children into several groups and analize the regulatory mechanism of GH. When we consider the GH responsiveness to GRF, we can not exclude the role of somatostatin and the effects of exogenous GH. Liapi (Liapi 1986) reported that a significant negative correlation between the amplitude of the peak GH after GRF injection, and the basal values of somatostatin-like immunoreactivity in short children.

It has been published that exogenous 
$\mathrm{GH}$ administrations suppress the $\mathrm{GH}$ responses to GRF (Nakamoto 1986). Our results also indicate that acute exogenous GH will suppress the responsiveness of somatotrophs to GRF, but this will be easily reversible even after chronic 1 year GH treatment in normal short children.

\section{Acknowledgement}

We thank Sumitomo Pharmaceuticals for generous supply of synthetic human GRF-44. This study was supported in part by Research Grants from the Ministry of Health and Welfare.

\section{References}

Argente, J., D. Evain-Brion, A. Munoz-Villa, P. Garnier, M. Hernandez and M. Donnadieu (1986). Relationship of plasma growth hormonereleasing hormone levels to pubertal changes. J. Clin. Endocrinol. Metab. 63, 680-682.

Chihara, K., H. Kodama, H. Kaji, T. Kita, Y. Kashio, Y. Okimura, H. Abe and T. Fujita (1985). Augmentation by propranolol of growth hormone-releasing hormone-induced growth hormone release in normal short and normal children. J. Clin. Endocrinol. Metab. 61, 229233.

Frohman L. A. and J. O. Jansson (1986). Growth hormone-releasing hormone. Endocrine Reviews 7, 223-253.

Gelato, M., O. H. Pescovitz, F. Cassorla, D. L. Loriaux and G. R. Merrian (1984). Doseresponses relationships for the effects of growth hormone-releasing factor-(1-44)- $\mathrm{NH}_{2}$ in young adult men and women. J. Clin. Endocrinol. Metab. 59, 197-201.

Gelato, M., S. Malozowski, M. Caruso-Nicoletti, J. L. Ross, O. H. Pescovitz, S. Rose, D. L. Loriaux, F. Cassorla and G. R. Merriam (1986). Growth hormon (GH) responses to GH-releasing hormone during pubertal development in normal boys and girls: Comparison to idiopathic short stature and GH deficiency. J. Clin. Endocrinol. Metab. 63, 174-179.

Guillemin, R., P. Brazeau, P. Böhlen, F. Esch, N. Ling and W. B. Wehrenberg (1982). Growth hormone releasing factor from a human pan- creatic tumor that caused acromegaly. Science 218, 585-587.

Laron, Z. and B. Bauman (1986). Growth hormone releasing hormone (GH-RH, GRF)an important new clinical tool. Eur. $J$. Pediatr. 145, 6-9.

Liapic, C., E. Brion, J. Argente, H. Vaudry and M. Donnadieu (1986). Negative correlation between peripheral plasma somatostatin levels and $\mathrm{GH}$ responses to GH-RH stimulation tests in children. Acta Endocrinol. 113, 1-4.

Nakamoto, J. M., J. M. Gertner, C. M. Press, R. L. Hintz, R. G. Rosenfeld and M. Genel (1986). Suppression of the growth hormone response to clonidine and GH-releasing hormone by exogenous GH. J. Clin. Endocrinol. Metab. 62, 822-826.

Pavlov, E. P., S. M. Harman, G. R. Merriam, M. C. Gelato, M. R. Blackman (1986). Responses of growth hormone (GH) and somatomedin-C to GH-releasing hormone in healthy aging men. J. Clin. Endocrinol. Metab. 62, 595-600.

Pointor, C., S. Loche, R. Puggioni, S. G. Cella, V. Locatelli, F. Villa, R. Corda and E. E. Muller (1986). Growth hormone response to hpGRF-44 in different forms of growth retardation and endocrine-metabolic diseases. Eur. J. Pediatr. 144, 475-481.

Rivier, J., J. Spiess, and M. Thorner (1982). Characterization of a growth hormone releasing factor from a human pancreatic islet tumor. Nature 300, 276-278.

Schriock, E. A., R. H. Lusting, S. M. Rosenthal, S. L. Kaplan and M. M. Grumbach (1984). Effect of growth hormone-releasing hormone on plasma $\mathrm{GH}$ in relation to magnitude and duration of GH deficiency in 26 children and adults with isolated GH deficiency or multiple pituitary hormone deficiencies: Evidence for hypothalamic GRF deficiency. J. Clin. Endocrinol. Metab. 58, 1043-1049.

Schriock, E. A., S. M. Rosenthal, C. A. Egli, D. A. Harris, B. P. Hauffa, J. A. Hulse, R. H. Lusting, S. L. Kaplan and M. M. Grumback (1986). Studies with growth hormonereleasing factor in the Human. Human Growth Hormone, ed. by S. Raiti and R. A. Tolman, Plenum Medical Book Co., N. Y. pp 387403.

Shibasaki, T., K. Shizume, M. Nakahara, A. Masuda, K. Jibiki, H. Demura, I. Wakabayashi and N. Ling (1984). Age-related changes in 
plasma growth hormone response to growth Williams, T., H. Maxon, M. O. Thorner and L. hormone-releasing factor in man. J. Clin. A. Frohman (1985). Blunted growth hormone Endocrinol. Metab. 58, 212-214.

Shimano, R. (1985). Studies on GH responses to hpGRF in infants. J. Jap. Pediatr. Soc. 89, response to GH-releasing hormone in hypothyroidism resolves in the euthyroid state. $J$. 2072-2077. 